\title{
Nanofinishing of FDM-fabricated components using ball end magnetorheological finishing process
}

\section{Aman Kumar, Zafar Alam, Dilshad Ahmad Khan \& Sunil Jha}

To cite this article: Aman Kumar, Zafar Alam, Dilshad Ahmad Khan \& Sunil Jha (2019)

Nanofinishing of FDM-fabricated components using ball end magnetorheological finishing process, Materials and Manufacturing Processes, 34:2, 232-242, DOI: 10.1080/10426914.2018.1512136

To link to this article: https://doi.org/10.1080/10426914.2018.1512136

曲 Published online: 05 Sep 2018.

Submit your article to this journal ๘

Џ Article views: 275

View Crossmark data $₫$

4

Citing articles: 1 View citing articles $\sqsubset$ 


\title{
Nanofinishing of FDM-fabricated components using ball end magnetorheological finishing process
}

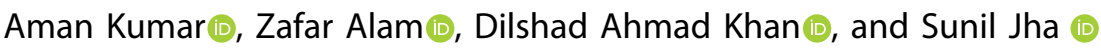 \\ Department of Mechanical Engineering, Indian Institute of Technology Delhi, New Delhi, India
}

\begin{abstract}
Fused deposition modeling (FDM) is among the extensively used and the most economical additive manufacturing processes. Currently, the surface finish obtained for FDM additive manufactured parts are not at par with the current industrial application. To overcome the limitation of high surface roughness of 3D printed parts, a novel finishing technique has been proposed which includes primary and secondary finishing processes. While facing and lapping has been used as primary finishing technique, the secondary finishing involves the use of ball end magnetorheological finishing (BEMRF) process. BEMRF process is an unconventional finishing process which utilizes an advanced approach to impart finish on magnetic as well as non-magnetic materials that may be flat or freeform in shape. This article presents the experimental and analytical study to finish a polylactic acid (PLA) workpiece material manufactured by FDM process and finished using the BEMRF technique. The surface roughness of the FDM component has been reduced from initial surface roughness $\mathrm{Ra}=20 \mu \mathrm{m}$ to final value of $\mathrm{Ra}=81 \mathrm{~nm}$ by combined primary and secondary finishing processes. The effect of magnetorheological polishing (MRP) fluid's composition and finishing time is discussed and is followed by optimization of MRP fluid for maximum percentage reduction in surface roughness.
\end{abstract}

\section{ARTICLE HISTORY}

Received June 62018

Accepted July 232018

\section{KEYWORDS}

Magnetorheological; ball; end; polishing; fluid; additive; manufacturing; surface; roughness

\section{Introduction}

Nowadays customized products such as biomedical implants ${ }^{[1]}$ are in high demands, but the conventional production techniques for products having complicated features are quite time-consuming and expensive. ${ }^{[2]}$ The evolution of the distinct technology of additive manufacturing (AM) has played a significant role in industries in developing cost-effective and difficult to manufactured part. Moreover, AM comes without the requirement of additional machine or tool setup and provides the required geometrical features without any cumbersome procedure. ${ }^{[3]} \mathrm{AM}$ process starts with the formation of virtual CAD model and generation of STL file which is further fed into one of the AM process for printing the physical model. The virtual model of components can also be obtained using the reverse engineering technique. Many different AM processes have conquered the market till now, they all differ in the types of raw material used, i.e., liquid, solid, or powder based, and their deposition techniques. Fused deposition modeling (FDM) is among the frequently used AM processes. In the FDM process, a solid thermoplastic filament is fused and deposited on the heated bed layer by layer through a nozzle. PLA and ABS are the commonly used polymers for FDM process that prevails in the market today for fabricating physical models. ${ }^{[4]}$ The $3 \mathrm{D}$ printing process of FDM has varied applications in automotive, aerospace and medical field. High surface roughness and low dimensional accuracy have been a challenging issue faced by the industry which is limiting the direct use of AM parts fabricated by FDM in many applications. This poor surface is due to the layer by layer deposition of the material, uneven shrinkage and residual stresses. The low surface finish in FDM is also caused by the staircase effect. ${ }^{[5]}$ To overcome this hindrance of poor surface finish, up to some extent, many pre- and post-processing methods have been devised so far.

The surface finish of the additively manufactured component can be improved by pre-processing as well as post-processing techniques. ${ }^{[6]}$ The pre-processing techniques include process parameter optimization and adaptive slicing. ${ }^{[7]}$ The process optimization is done by varying the fabrication related parameters viz. build orientation, ${ }^{[8]}$ thickness of each layer, raster/counter width, raster angle, and temperature of the model. ${ }^{[9]}$ The adaptive slicing technique operates as a balance between the surface finish and the time to build the product. This technique is followed by tessellated CAD model and direct slicing. The most effective method of improving surface finish is by optimizing the layer thickness. However, reducing too much layer thickness leads to longer build time which is also not advisable. ${ }^{[10]}$

The post-processing technique is further subdivided into mechanical and chemical methods. The conventional mechanical methods are adapted after production phase, and the process includes manual sanding, abrasive milling, and abrasive flow machining. ${ }^{[11]}$ Moreover, some additional post finishing methods are sand blasting, vibratory bowl finishing, barrel tumbling, hot cutter machining, ball burnishing, and CNC machining ${ }^{[6]}$ Some chemical techniques involve vapor surface polishing, ${ }^{[12]}$ manual painting, acetone dipping, vapor smoothing, and electroplating. ${ }^{[13]}$ Using the chemical method the surface finish of the AM part has been found to be reduced between $2 \mu \mathrm{m}$ and 
$9 \mu \mathrm{m}$. The drawbacks of the chemical finishing method is that they require material's in-depth knowledge and only ABS material has been investigated with the process till date. Another limitation is that this process might not be able to finish the component evenly throughout the surface. ${ }^{[14]}$

In this article, the surface roughness improvement of FDM fabricated components has been attempted using a post-processing magnetic assistive technique ${ }^{[15]}$ called ball end magnetorheological finishing (BEMRF) ${ }^{[16]}$ a magnetically controlled technique which is capable of finishing flat as well as three dimensional freeform surfaces ${ }^{[17-19]}$ up to nano level. BEMRF's finishing capability lies in a varied range of materials such as aluminum, copper, ${ }^{[20]}$ polycarbonate, ${ }^{[21]}$ silicon, ${ }^{[22]}$ and EN31 steel. The 5-axis CNC machine setup used in this study consists of CNC controller, spindle, rotary valve, MR finishing tool, linear slides, power supply, and cooling bath for electromagnet cooling. Electrolytic iron particles (EIPs) and polishing grade abrasives along with distilled water-based carrier medium are the constituents of magnetorheological polishing (MRP) fluid used in this technique.

In BEMRF process, a spindle is surrounded by an electromagnet and at the tip of the spindle MRP fluid is applied. When the electromagnet is energized, the MRP fluids orient itself in the direction of magnetic field and get morphed into a hemispherical ball as shown in Fig. 1. As compared to the workpiece the tip of the tool is in the vicinity of an electromagnet which leads to the formation of magnetic flux density gradient between the workpiece and the tip of the tool. This results in the movement of EIPs toward tool tip pushing the abrasive to move toward workpiece top surface. While normal force produced due to this action causes the piercing of abrasive into the workpiece's surface, it is the shear force that leads to shearing of the roughness peaks (Fig. 1). Also, an increase in the viscosity of the MRP fluid is which imparts the necessary shear strength for the cutting action to be performed by the gripped abrasives. ${ }^{[23]}$

This article presents the experimental study of FDM fabricated component's surface finished by post-processing technique that includes mechanical finishing technique, i.e., primary and secondary finishing processes. For secondary finishing process using BEMRF, the effect of abrasives and EIP's concentration on percent change in roughness value of workpiece is evaluated which is further followed by MRP fluid optimization. The significant surface characteristics discussed here is surface roughness, and the detailed methodology has been mentioned in the next section.

\section{Materials and methods}

Figure 2 shows the flowchart depicting the process flow of $3 \mathrm{D}$ printed part finishing. The workpiece that is needed for a specific application using FDM process could be scaled up at the CAD model stage so that the additional material is trimmed off using the primary finishing process and the final finished geometry is obtained as required.

The primary finishing process that can be used here for post-processing technique includes facing, turning, ${ }^{[24]}$ precision grinding, ${ }^{[15]} \mathrm{CNC}$ milling, ${ }^{[25]}$ etc. depending upon the geometry of the workpiece. In case where CNC machine is being used for primary finishing instead of a manual machining process,

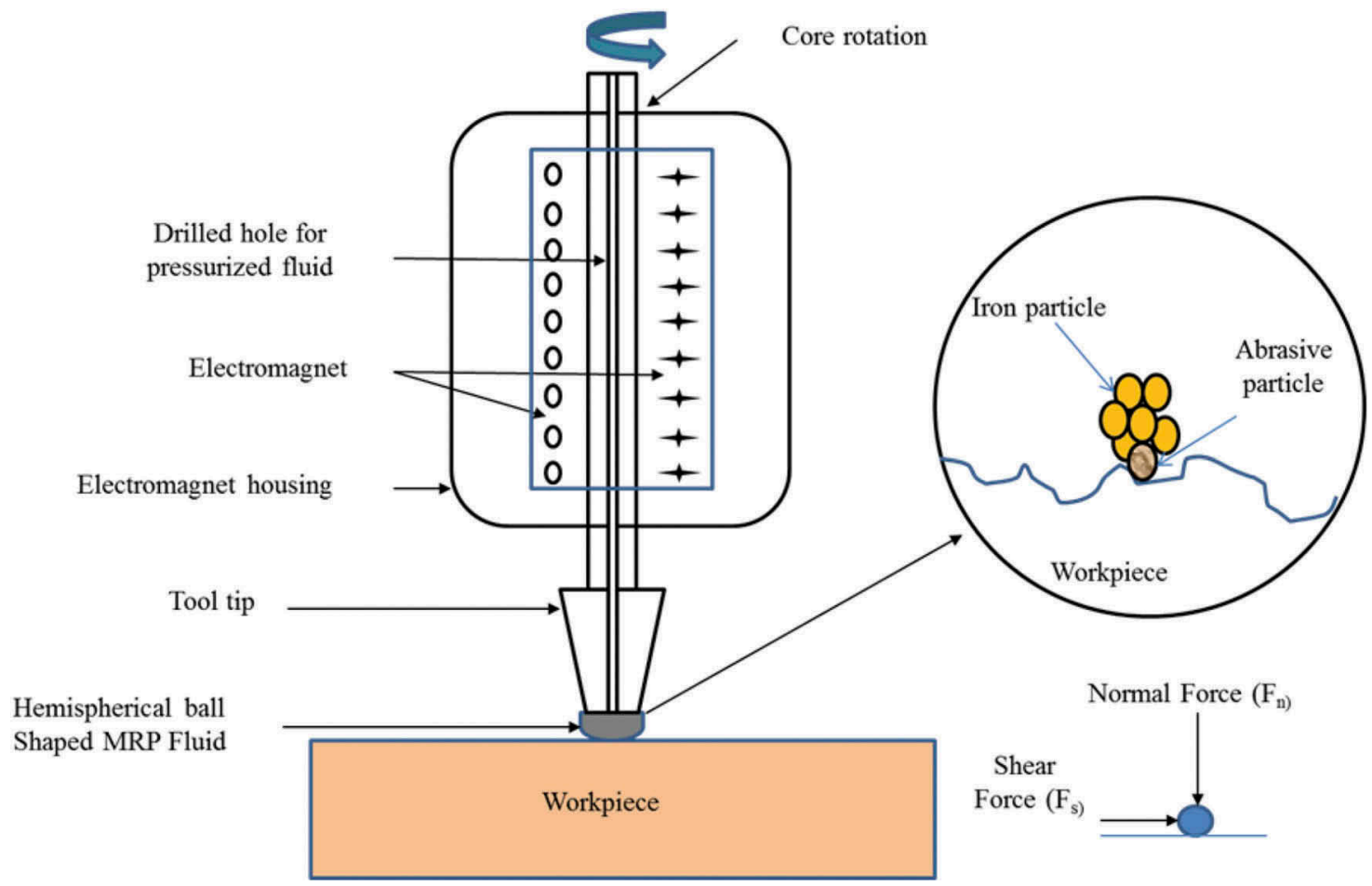

Figure 1. Mechanism of material removal in BEMRF process. 


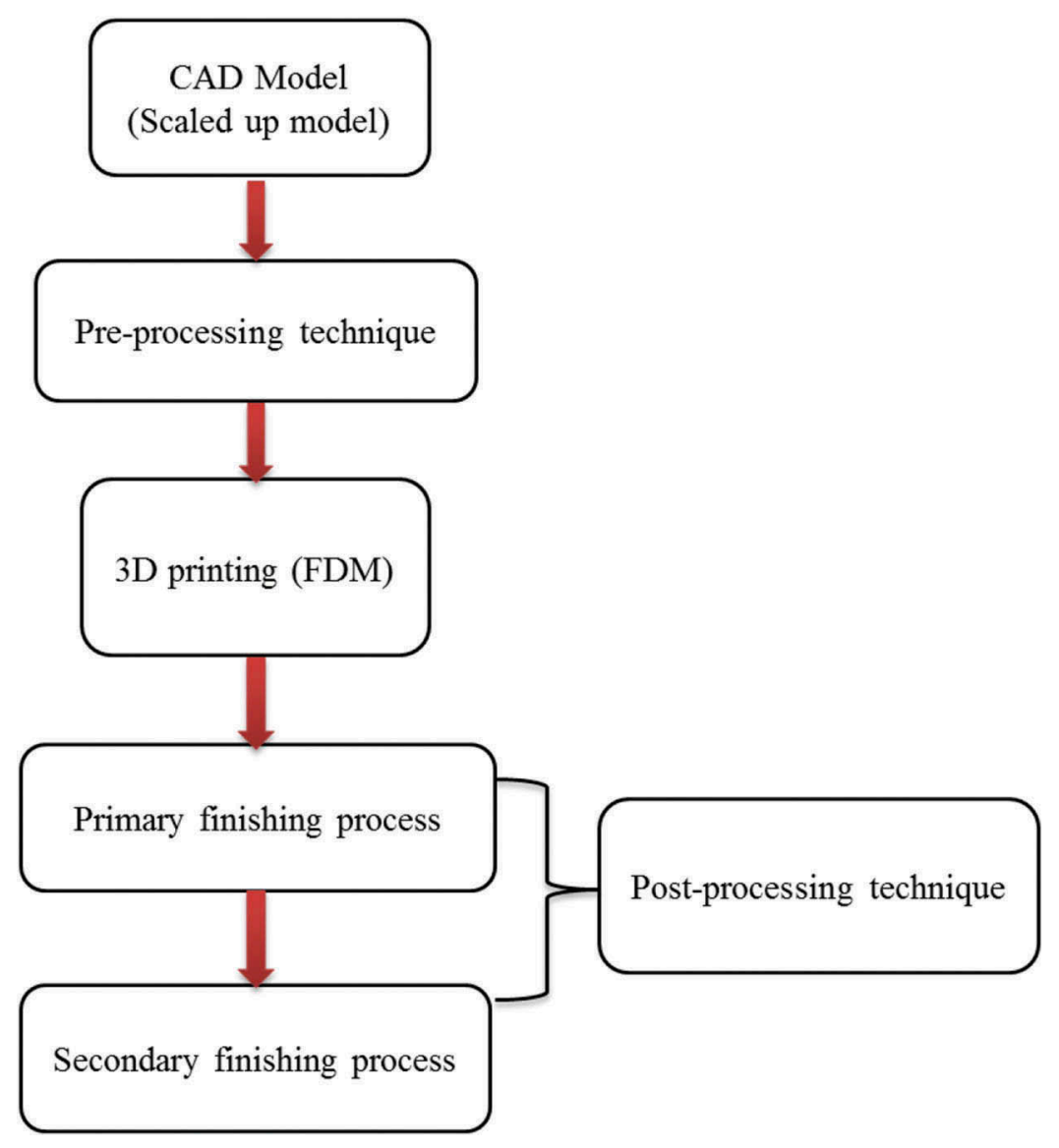

Figure 2. Flowchart showing the process of finishing of 3D printed part.

the same CAD model, used for $3 \mathrm{D}$ printing, is needed to be imported in CAM software so that exact tool path can be generated. ${ }^{[25]}$ Then the G-code generated for the tool path can be fed to the CNC machine and machining of any kind of freeform surface of the 3D printed part can be done.

The workpiece adopted for performing experiments is a $3 \mathrm{D}$ printed PLA material built using FDM process. The process parameters used for fabrication of the physical model is mentioned in Table 1. Figure 3 shows the CAD model, generated STL file and the actual image of the cuboid-shaped workpiece $50 \times 50 \times 8 \mathrm{~mm}^{3}$. The 3D printed surface is first finished using a primary finishing process. For this purpose, a four-jaw chuck lathe machine was used for facing of the component in order to flatten the height between two adjacent layers of the PLA material. Sequentially, lapping was done with the emery paper. This ensures further reduction of the surface roughness and removal of unevenness from the workpiece. The initial surface roughness of FDM fabricated components which are in the order of $16-60 \mu \mathrm{m}$ can be reduced up to $1-5 \mu \mathrm{m}$

Table 1. FDM process parameters.

\begin{tabular}{ll}
\hline Parameters & Conditions \\
\hline Bed temperature & $65^{\circ} \mathrm{C}$ \\
Nozzle temperature & $220^{\circ} \mathrm{C}$ \\
Infill density & $40 \%$ \\
Wall thickness & $1 \mathrm{~mm}$ \\
Extrusion width & $0.40 \mathrm{~mm}$ \\
Layer thickness & $0.15 \mathrm{~mm}$ \\
Filament material \& diameter & $\mathrm{PLA}, 1.75 \mathrm{~mm}$ \\
\hline
\end{tabular}

following the primary finishing process. ${ }^{[24]}$ After lapping process is performed on the workpiece, the surface roughness can be reduced up to $500 \mathrm{~nm}-2 \mu \mathrm{m}$. The primary finishing step is very crucial prior to performing the secondary finishing process using BEMRF machine.

Since the initial surface roughness is too much to start the secondary finishing process using BEMRF, a primary finishing method is needed to perform the initial finishing of the part. The nanofinishing technique (BEMRF) is meant to be applied when the surface is already finished up to $1-2 \mu \mathrm{m}$ otherwise no significant results would be obtained. Also, it is obvious to note that when the BEMRF process is applied directly (without any prior primary finishing process) on the 3D printed surface, the MRP fluid will penetrate inside the surface of the part making the removal of the surface MRP fluid impossible which will eventually damage the workpiece and will require further removal of layers using additional machining causing the overall dimensional error.

The primary finishing process used here for experimentation is 'facing' on a four jaw chuck lathe as shown in Fig. 4(a). Since facing is suitable only for a flat surface with limitations of the maximum dimension that chuck can hold, CNC milling process can be used for doing the primary finishing process on any kind of surface including the freeform surface. Furthermore, lapping is carried out before finally finishing with the BEMRF machine to lower the unevenness of the part produced by $3 \mathrm{D}$ printing. The different grades of emery papers viz. 800, 1000, and 1200 were used to perform the lapping on the surface obtained after primary 

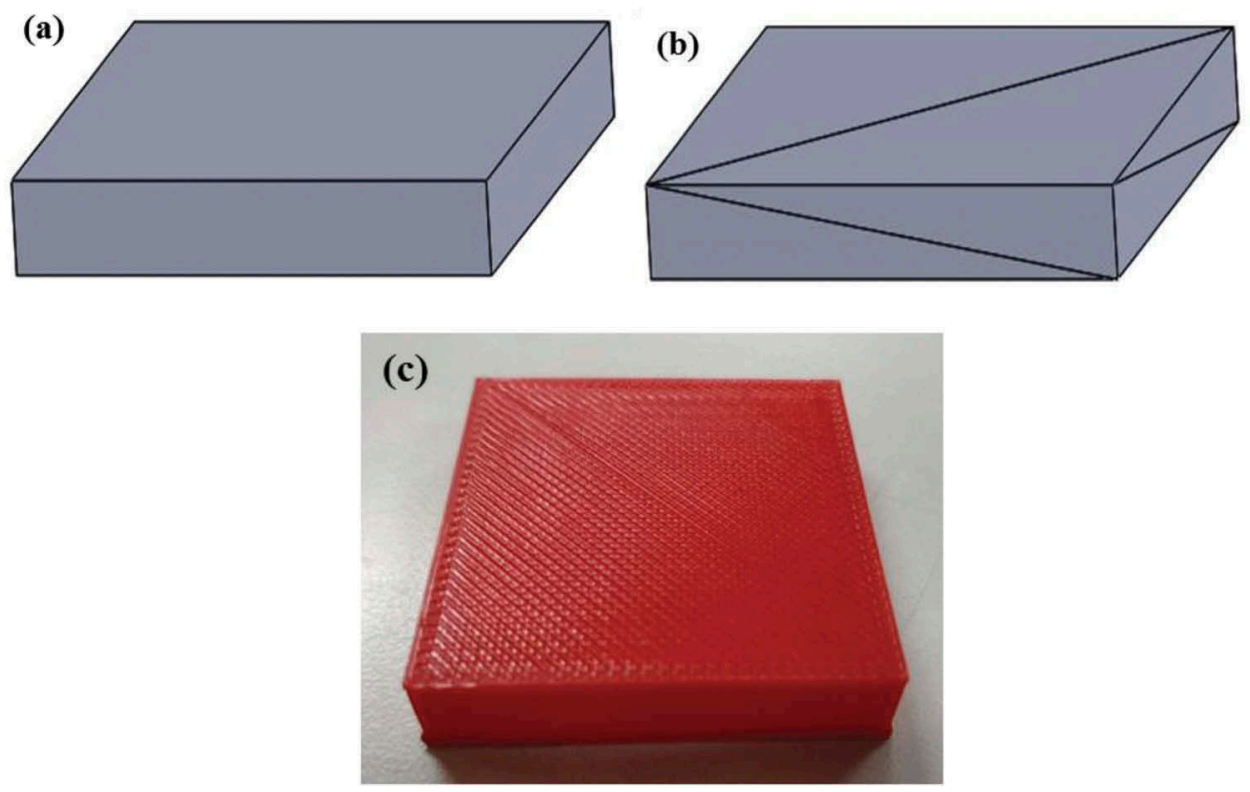

Figure 3. (a) CAD model, (b) STL file generated for 3D printing and (c) 3D printed part used as the workpiece.
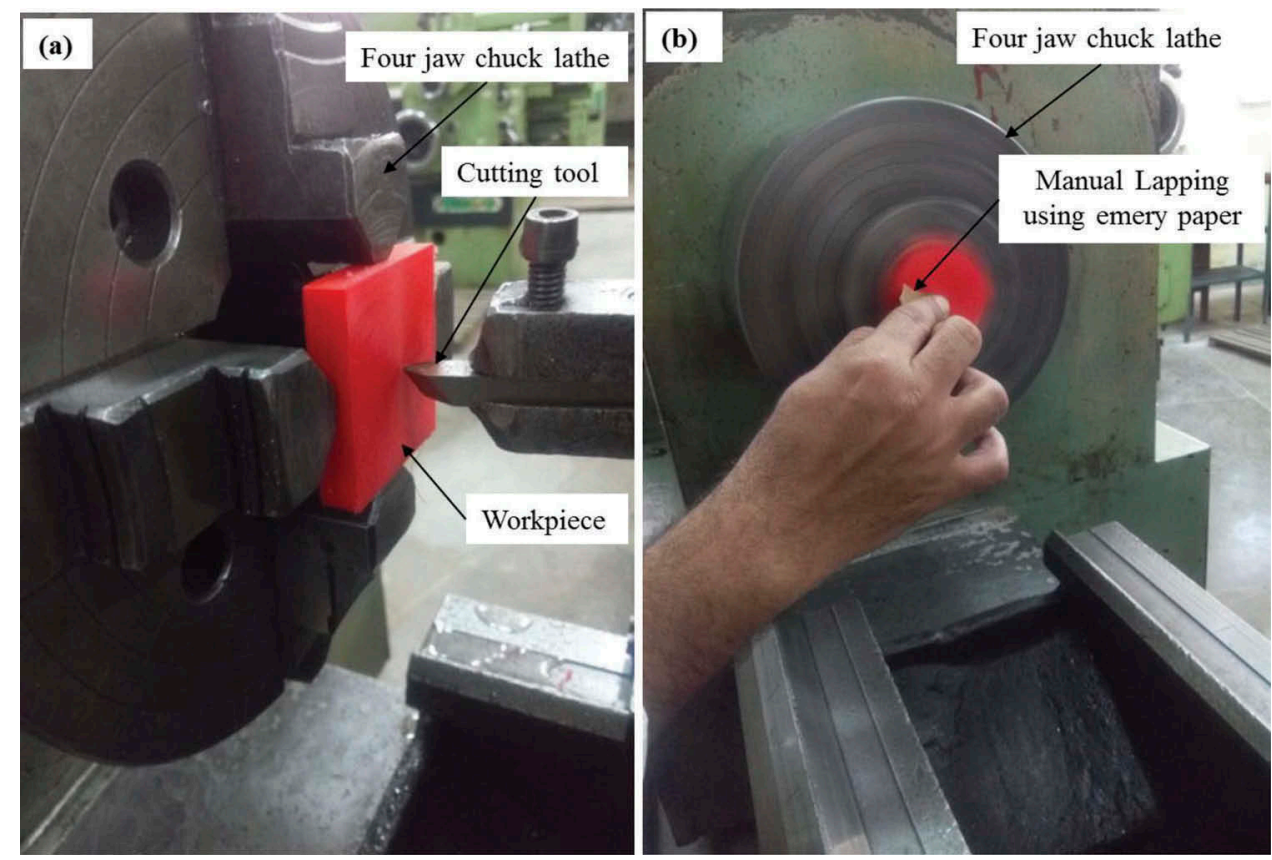

Figure 4. (a) Facing on four-jaw chuck lathe machine and (b) lapping process after facing.

finishing process. This ensures the reduction of initial surface roughness in the order of few microns/nanometers. To avoid removal of the workpiece and mounting again on a lapping machine, the lapping was performed on the lathe machine itself as shown in Fig. 4(b). For a freeform surface manual free-hand lapping can be done after $\mathrm{CNC}$ machining to reduce the surface roughness and impart evenness in the surface. Initially, experimentation was done with water-based MR polishing fluid using three types of abrasives namely Alumina $\left(\mathrm{Al}_{2} \mathrm{O}_{3}\right)$ of mesh size 1000, Silicon carbide $(\mathrm{SiC})$ of mesh size 1000, and Boron carbide
$\left(\mathrm{B}_{4} \mathrm{C}\right)$ of mesh size 1000. For all these fluids, EIP was used as the ferromagnetic material.

The selection of abrasive was done after performing some preliminary experiments with various types of abrasive mixed with EIP and distilled water as the carrier fluid. From the preliminary experiments carried out to test the suitability of type of abrasive for finishing of PLA based FDM AM part, it was observed that Silicon carbide $(\mathrm{SiC})$ and Boron carbide $\left(\mathrm{B}_{4} \mathrm{C}\right)$ did not have any significant finishing results on FDM fabricated part, while Alumina yielded substantially better results. Therefore, Alumina 
$\left(\mathrm{Al}_{2} \mathrm{O}_{3}\right)$ of mesh size 1000 was selected for further experimentation.

All the experiments were performed with the workpieces being mounted on the precision vice of a 5-axis CNC BEMRF machine, as shown in Fig. 5(a). The electromagnet coil was energized with 6 amperes direct current. The rotational speed of the tool spindle was set at $300 \mathrm{rpm}$, the feed was $40 \mathrm{~mm} /$ min and the working gap was maintained at $0.8 \mathrm{~mm}$. In this study, the effect of variation of fluid composition has been studied. Figure 5(b) shows the BEMRF's tool tip along with the polishing fluid in action. The constant parameters used for all the experiments along with the respective conditions are mentioned in Table 2.

The average surface roughness value of initial as well as the final finished surface was measured using contact type stylusbased Taylor Hobson's Talysurf instrument. The measurement length was taken as $4 \mathrm{~mm}$ and the cutoff length was $0.8 \mathrm{~mm}$. A plastic film template was used to measure the Ra value of initial and final surface at the same location on the workpiece.

Abrasive and EIP concentration plays a significant part in finishing results during BEMRF process and the effect of both of them in finishing has been explained in further section. A central composite rotatable design scheme was implemented for experimentations to analyze the responses of the effect of fluid composition parameters. In the design scheme, two factors were taken at five levels. The abrasive and EIP concentration (indicated by $\mathrm{A}$ and $\mathrm{B}$ respectively) was differed from 10 to 20 vol\% and 15 to $25 \mathrm{vol} \%$, respectively. The range of abrasive and EIP were decided to keep the viscosity of the polishing fluid maintained.

Due to unevenness in initial surface roughness measurement values, the percent reduction in $\mathrm{Ra}$ has been considered for measurement and it is computed using Eq. (1).

$\begin{aligned} \% \Delta \mathrm{Ra}= & \left(\frac{\text { Initial surface roughness }- \text { Final surface roughness }}{\text { Initial surface roughness }}\right) \\ & \times 100\end{aligned}$

To analyze the significance of the regression equation, analysis of variance (ANOVA) was adopted. Using ANOVA, the relationship between the MRP fluid composition and the response $\% \Delta \mathrm{Ra}$ is delineated. The five levels of the factors of the fluid composition are shown in Table 3 along with their coded and actual values.

To examine the fluid composition parameters' effect on $\%$ $\Delta \mathrm{Ra}$, a total of 13 experiments were performed in random order and the experimentation plan accompanied by their responses are compiled in Table 4 . It is to be noted that the 'Initial Ra' column mentioned in Table 4 represents the $\mathrm{Ra}$ measured for FDM workpiece after primary finishing process, i.e., facing and lapping.

All model terms of analysis of variance are shown in Table 5. The acceptability of the model is implied by $\mathrm{F}$ value 52.83 and $p$ value less than 0.05. In this ANOVA table, all model terms, i.e., $\mathrm{A}-\mathrm{A}, \mathrm{B}-\mathrm{B}, \mathrm{AB}, \mathrm{A}^{2}$, and $\mathrm{B}^{2}$ are having the $p$-value less than 0.05 and, hence, all are significant terms. When it comes to 'Lack of fit,' it is desirable that it is non-significant and from the ANOVA table, the $p$-value is 0.0944 which is greater than 0.05 ; therefore, it is termed as 'not significant.'

The coefficient of correlation, $\mathrm{R}^{2}=0.97$, shows that there is a good relation between measured and calculated values of the outputs. Also, for the regression models the predicted $\mathrm{R}^{2}$ is usually in accord with adjusted $\mathrm{R}^{2}$ when the difference between the two is within 0.2. For the developed model, values of adjusted and predicted $\mathrm{R}^{2}$ are 0.95 and 0.85 , respectively and the difference between them is 0.10 which is within the limit.

In terms of actual factors, the developed regression model from central composite design is illustrated through Eq. (2)

$$
\begin{aligned}
\% \Delta \mathrm{Ra}= & 0.74650+7.59055 \mathrm{~A}-3.30124 \mathrm{~B}+0.096939 \mathrm{AB} \\
& -0.30921 \mathrm{~A}^{2}+0.074459 \mathrm{~B}^{2}
\end{aligned}
$$

\section{Results and discussion}

The abrasive concentration's effect on $\% \Delta \mathrm{Ra}$ is shown in Fig. 6. As observed from the figure, the change in $\% \mathrm{Ra}$ increases up to a certain extent with increase in abrasive concentration in MRP fluid and then starts decreasing. The reason for this trend can be explained due to the following phenomenon. Abrasive is the main cutting element in the MRP fluid, so as the concentration
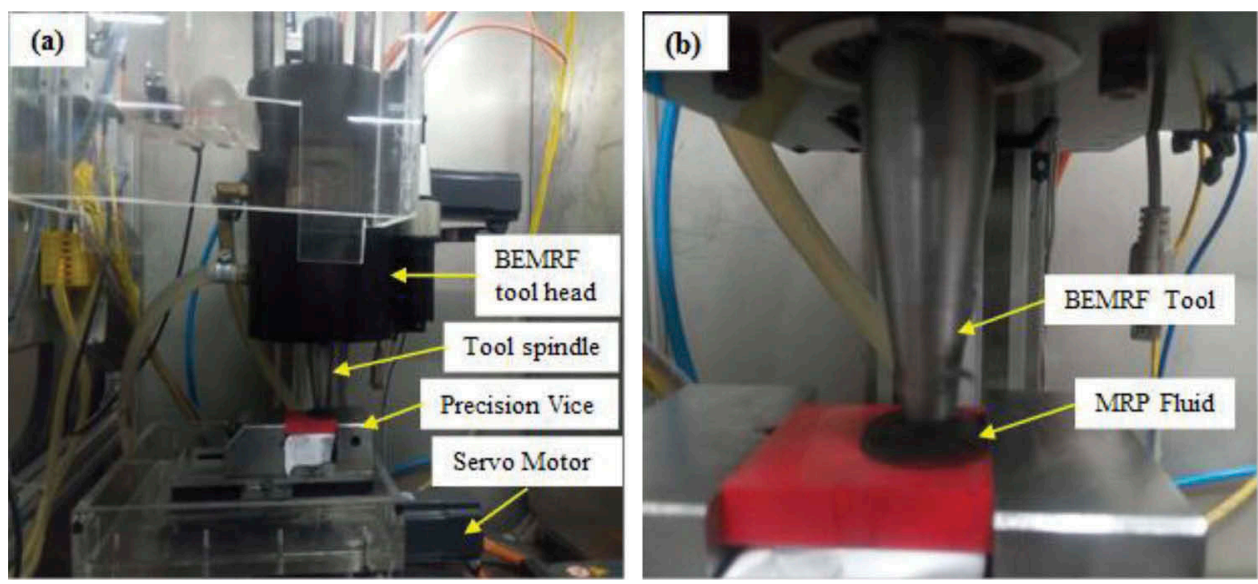

Figure 5. (a) BEMRF machine performing finishing action and (b) Finishing tool with MRP fluid. 
Table 2. Experimental parameters.

\begin{tabular}{ll}
\hline Parameters & Conditions \\
\hline Abrasive type and size & Alumina $\left(\mathrm{Al}_{2} \mathrm{O}_{3}\right)$, mesh size 1000 \\
Electrolytic Iron particles (EIPs) size & 300 mesh size \\
Base fluid & Distilled water \\
Magnetizing current & $6 \mathrm{~A}$ \\
Working gap & $0.8 \mathrm{~mm}$ \\
Rotational speed & $300 \mathrm{rpm}$ \\
Table feed rate & $40 \mathrm{~mm} / \mathrm{min}$ \\
Finishing time & $30 \mathrm{~min}$ \\
Finishing length & $10 \mathrm{~mm}$ \\
\hline
\end{tabular}

Table 3. Coded levels and actual values of fluid composition.

\begin{tabular}{llccccc}
\hline & & \multicolumn{5}{c}{ Levels } \\
\cline { 3 - 7 } S. No. & Parameters & -1.414 & -1 & 0 & +1 & +1.414 \\
\hline 1 & Abrasive concentration (vol\%), A & 10 & 11.5 & 15 & 18.5 & 20 \\
2 & EIP concentration (vol\%), B & 15 & 16.5 & 20 & 23.5 & 25 \\
\hline
\end{tabular}

Table 4. Plan of experiments and response.

\begin{tabular}{|c|c|c|c|c|c|c|c|c|}
\hline \multirow{3}{*}{$\begin{array}{l}\text { Std } \\
\text { Order }\end{array}$} & \multirow[b]{3}{*}{$\begin{array}{l}\text { Run } \\
\text { Order }\end{array}$} & \multicolumn{4}{|c|}{ Input Parameters } & \multirow{3}{*}{$\begin{array}{l}\text { Initial Ra } \\
\text { value } \\
(\mathrm{nm})\end{array}$} & \multirow{3}{*}{$\begin{array}{l}\text { Final Ra } \\
\text { value } \\
(\mathrm{nm})\end{array}$} & \multirow[b]{3}{*}{$\begin{array}{l}\% \Delta \\
\mathrm{Ra}\end{array}$} \\
\hline & & \multicolumn{2}{|c|}{ Coded levels } & \multicolumn{2}{|c|}{$\begin{array}{l}\text { Actual values } \\
\text { (vol\%) }\end{array}$} & & & \\
\hline & & Abrasive & EIP & Abrasive & EIP & & & \\
\hline 1 & 5 & -1 & -1 & 11.5 & 16.5 & 574 & 402 & 29.97 \\
\hline 2 & 9 & +1 & -1 & 18.5 & 16.5 & 502 & 350 & 30.28 \\
\hline 3 & 10 & -1 & +1 & 11.5 & 23.5 & 544 & 345 & 36.58 \\
\hline 4 & 11 & +1 & +1 & 18.5 & 23.5 & 538 & 314 & 41.64 \\
\hline 5 & 2 & -1.414 & 0 & 10 & 20 & 582 & 407 & 30.07 \\
\hline 6 & 3 & +1.414 & 0 & 20 & 20 & 569 & 391 & 31.28 \\
\hline 7 & 12 & 0 & -1.414 & 15 & 15 & 579 & 375 & 35.23 \\
\hline 8 & 13 & 0 & +1.414 & 15 & 25 & 512 & 282 & 44.92 \\
\hline 9 & 7 & 0 & 0 & 15 & 20 & 561 & 351 & 37.43 \\
\hline 10 & 6 & 0 & 0 & 15 & 20 & 533 & 335 & 37.15 \\
\hline 11 & 1 & 0 & 0 & 15 & 20 & 601 & 368 & 38.77 \\
\hline 12 & 8 & 0 & 0 & 15 & 20 & 592 & 367 & 38.01 \\
\hline 13 & 4 & 0 & 0 & 15 & 20 & 550 & 341 & 38 \\
\hline
\end{tabular}

Table 5. Analysis of variance (ANOVA) for $\% \Delta$ Ra.

\begin{tabular}{lcccccc}
\hline & Sum of & \multicolumn{1}{c}{ Mean } & $\mathrm{F}$ & $p$-Value & \\
Source & Squares & DF & Square & Value & Prob $>\mathrm{F}$ & Remark \\
\hline Model & 251.12 & 5 & 50.22 & 52.83 & $<0.0001$ & Significant \\
A-A & 6.27 & 1 & 6.27 & 6.59 & 0.0371 & \\
$\mathrm{~B}-\mathrm{B}$ & 125.40 & 1 & 125.40 & 131.91 & $<0.0001$ & \\
$\mathrm{AB}$ & 5.64 & 1 & 5.64 & 5.93 & 0.0450 & \\
$\mathrm{~A}^{2}$ & 99.81 & 1 & 99.81 & 104.99 & $<0.0001$ & \\
$\mathrm{~B}^{2}$ & 5.79 & 1 & 5.79 & 6.09 & 0.0430 & \\
Residual & 6.65 & 7 & 0.95 & & & Not \\
Lack of Fit & 5.10 & 3 & 1.70 & 4.36 & 0.0944 & significant \\
& & & & & & \\
Pure Error & 1.56 & 4 & 0.39 & & & \\
Cor Total & 257.77 & 12 & & & & \\
\hline
\end{tabular}

of abrasive increases, it increases the number of cutting particles in MRP fluid. Hence, more particles lead to increase in more cutting action performed on the peaks of the surface. However, beyond a certain concentration of abrasive in the MRP fluid, $\% \Delta \mathrm{R}_{\mathrm{a}}$ decreases. This is because abrasive particles are non-magnetic in nature and their higher concentration decreases the MRP fluid's magnetic permeability. This hampers the chain formation during the energization process of the MRP fluid which results in the decrease of $\% \Delta \mathrm{Ra}$.

From the result of the effect of concentration of EIP, it is noticed that as the EIP concentration increases in the MRP fluid, $\% \Delta \mathrm{R}_{\mathrm{a}}$ increases. The EIP is the main constituent in the MRP fluid which is responsible for MR effect. So as the EIP concentration increases the fluid becomes more magnetic in nature and grips the abrasive particles firmly while finishing. That results in an increase in $\% \Delta \mathrm{Ra}$ with the increase in EIP concentration in MRP fluid. From the Fig. 7, it is also observed that with the increase in abrasive concentration, \% $\triangle \mathrm{Ra}$ increases but for the volume concentration $18.5 \%$ and above, $\% \Delta \mathrm{Ra}$ starts decreasing. At higher abrasive volume concentration the MRP fluid's permeability decreases which leads to the formation of weak EIP chains that results in nonfirmly gripping of abrasives. Therefore, it results in the decrease in $\% \Delta \mathrm{Ra}$ on increasing the abrasive concentration beyond $18.5 \%$. The same phenomenon could be observed from the graph of 20 vol\% of abrasives.

The combined effect of both parameters on $\% \Delta \mathrm{Ra}$ is depicted by three-dimensional surface plots in Fig. 8. The 3D surface plot helps in understanding the variation of $\%$ $\Delta \mathrm{Ra}$ at different values of parameters.

In the optimization study, the response function has been maximized (denoted by Eq. (2)) in order to obtain the highest reduction in $\% \Delta \mathrm{Ra}$ subjected to optimal amount of input parameters. For this, the quadratic model achieved by regression analysis is optimized further within the design space. To obtain the maximum value of $\% \Delta \mathrm{Ra}$ at optimal fluid constituents Design Expert software was utilized. For maximizing Eq. (2), the limits are:

$$
\begin{aligned}
& 10 \leq \mathrm{A} \leq 20 \\
& 15 \leq \mathrm{B} \leq 25
\end{aligned}
$$

The maximization function yields $16.17 \mathrm{vol} \%$ of abrasives and $25 \mathrm{vol} \%$ of EIP as the optimum fluid composition. To validate the developed regression model and the optimized results, two experiments have been conducted on randomly chosen parameters and one experiment has been performed on the optimized value of abrasive and EIP concentration and their results have been enumerated in Table 6. From the table, it is to be noticed that the error between predicted and experimental value comes out to be $0.48 \%$ at the optimum concentration values, which is very good. Even for the regression model, the errors are within acceptable limits.The optimized MRP fluid composition consists of $16.17 \mathrm{vol} \%$ of abrasives, $25 \mathrm{vol} \%$ of EIP, and $58.83 \mathrm{vol} \%$ of distilled water as the carrier fluid.

For studying the critical limit of minimum surface roughness that can be achieved by the optimum fluid concentration, a fresh primary-finished FDM workpiece sample was finished intermittently with the optimized MRP fluid composition for $15 \mathrm{~min}$ of time interval and the surface roughness after each $15 \mathrm{~min}$ is recorded. The Ra values achieved at the end of each $15 \mathrm{~min}$ finishing cycle are shown in Fig. 9. The initial Ra of the primary finished FDM part was $511 \mathrm{~nm}$. From Fig. 9, it can be perceived that the surface finish improves up to $75 \mathrm{~min}$ of finishing and then it starts decreases. This is due to the fact that the critical value of surface roughness is achieved at the parameters fixed for the experiments and after that the abrasive and EIPs tend to rub the workpiece instead of performing 


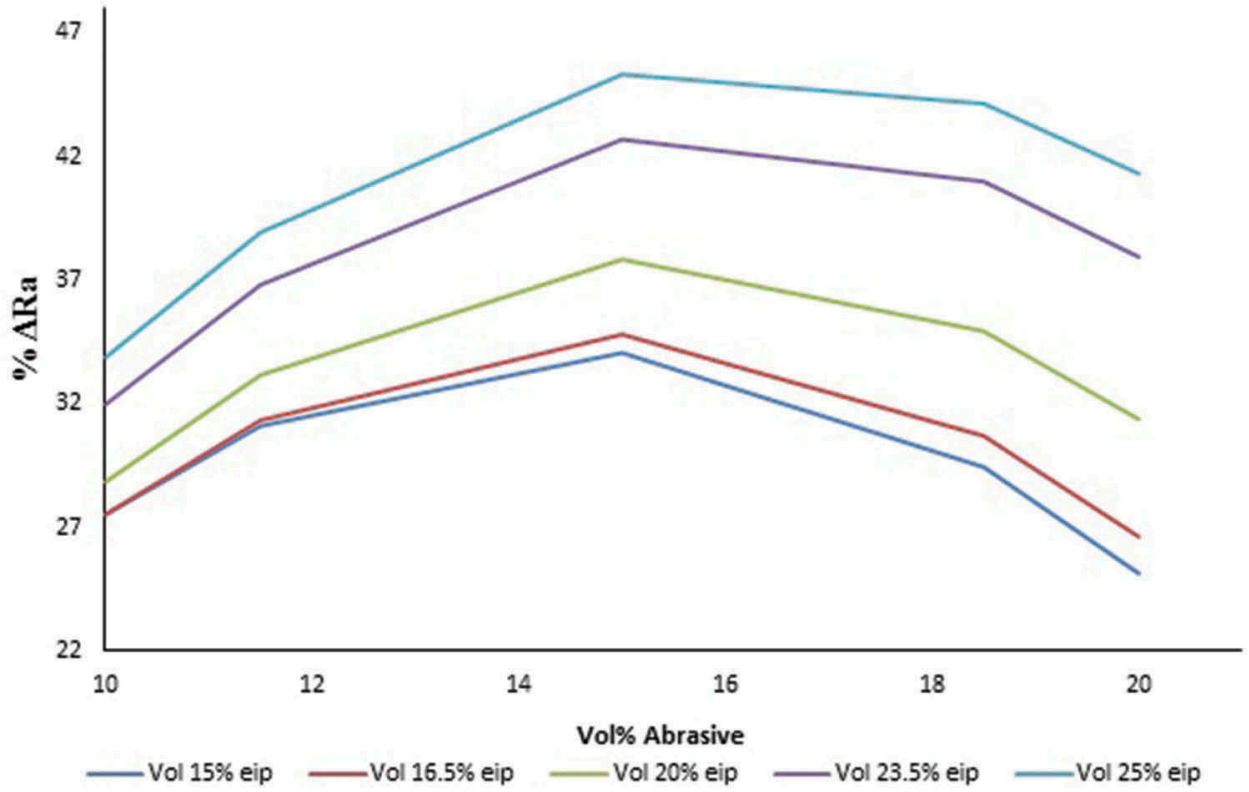

Figure 6. Effect of abrasive concentration on $\% \Delta R a$.

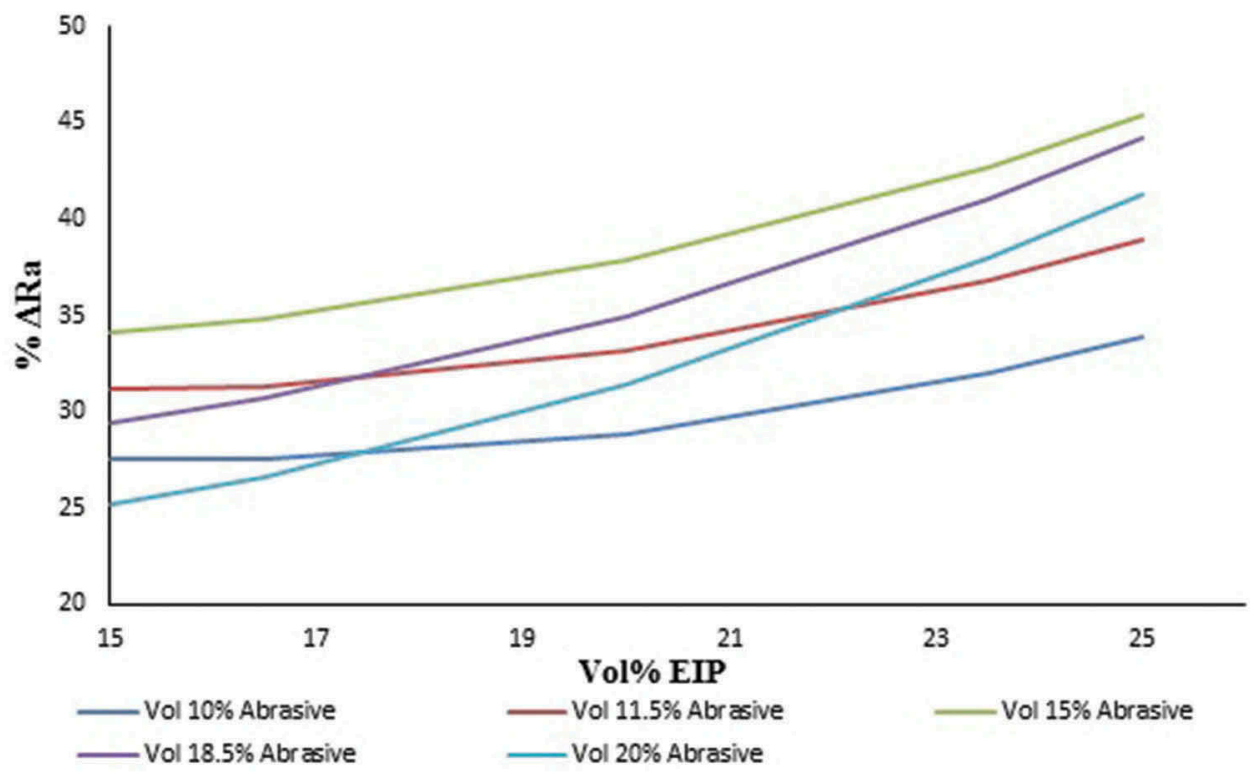

Figure 7. Effect of EIP concentration on $\% \Delta$ Ra.

further cutting action. Due to rubbing action, the surface roughness increases to $97 \mathrm{~nm}$ from the minimum obtained $81 \mathrm{~nm}$. This shows that $81 \mathrm{~nm}$ is the critical value of the maximum surface finish that can be achieved with this optimal MRP fluid composition.

The surface roughness profiles of primary finished FDM workpiece surface $(511 \mathrm{~nm})$ and after $75 \mathrm{~min}$ of BEMRF $(81 \mathrm{~nm})$ are shown in Fig. 10 (a) and (b), respectively. The actual photographs of the initial and final surface obtained by 75 min of finishing using optimized MRP fluid composition are shown in Fig. 11. The reflection on the finished region of the FDM workpiece (Fig. 11(b)) depicts the quality of finished surface obtained.
An optical microscope was utilized to observe the surface characteristics of the post-processed FDM printed sample, i.e., after primary and secondary finishing operations. Figure 12 shows the micrographs taken at 100x using the optical microscope (Leica M205a). Figure 12(a) shows the micrograph of the workpiece after primary finishing operations (i.e., after facing and lapping). It can be clearly observed from Fig. 12(a) that the workpiece is having scratch marks on the surface which even after performing facing and manual lapping is not removed. However, it can be noticed that the fused layer of PLA material deposited adjacently has been flattened completely with tangible scratch marks. Figure 12(b) shows the micrograph of the workpiece after secondary finishing 


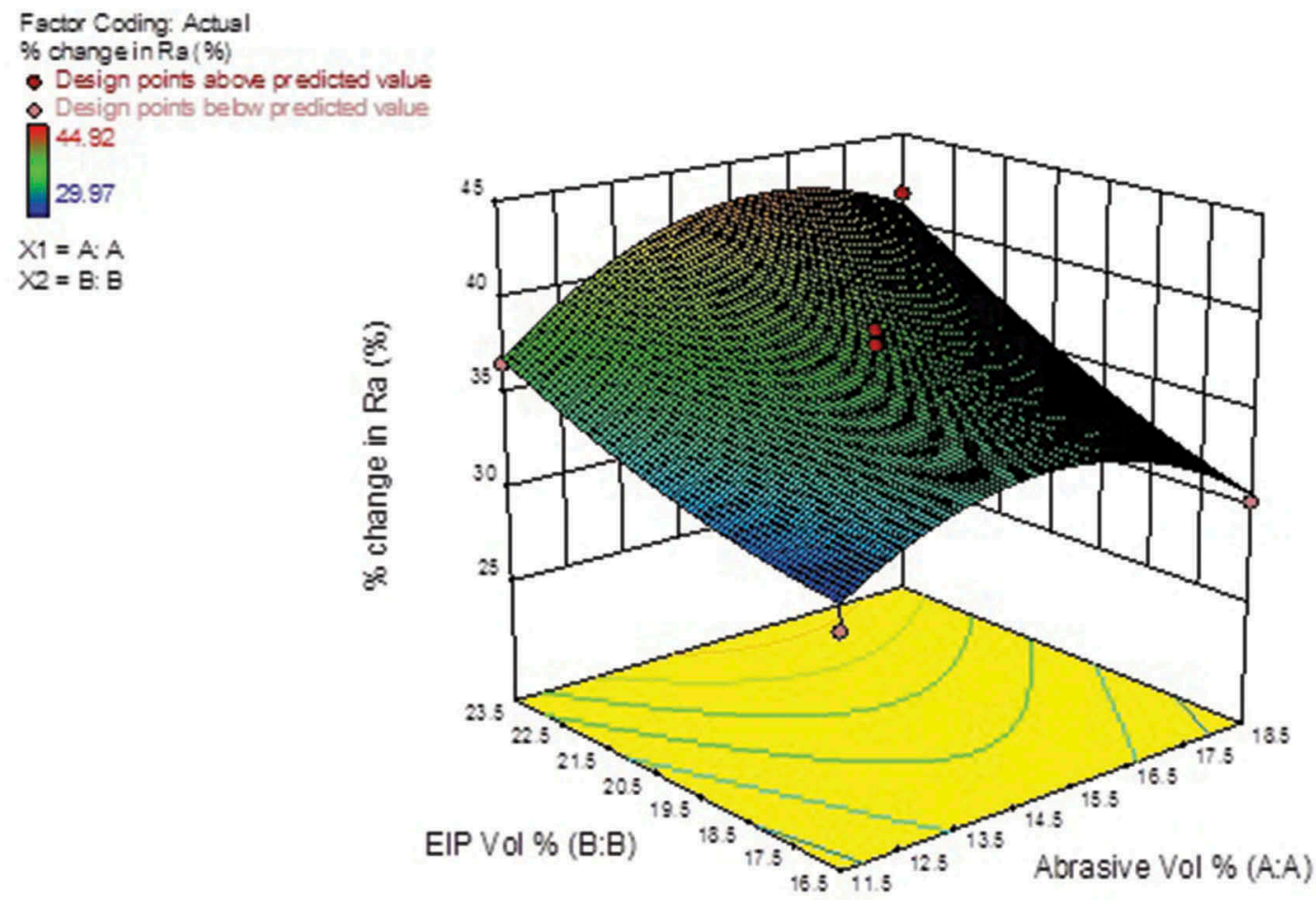

Figure 8. 3D surface plot showing $\% \Delta \mathrm{Ra}$ at different values of abrasive (denoted by $\mathrm{A}$ ) and EIP concentration (denoted by $\mathrm{B}$ ).

Table 6. Validation of regression model along with optimum values.

\begin{tabular}{lcccc}
\hline Parameters & & & & \\
\cline { 1 - 3 } & & $\begin{array}{c}\text { Predicted } \% \Delta \mathrm{Ra} \\
\text { by a quadratic } \\
\text { model }\end{array}$ & $\begin{array}{c}\text { Experimental } \\
\% \Delta \mathrm{Ra}\end{array}$ & $\begin{array}{c}\text { Error in } \\
\text { the } \\
\text { predicted } \\
\text { value }\end{array}$ \\
$\mathrm{A}$ & $\mathrm{B}$ & 31.34 & 29.97 & 4.37 \\
$11.5 \mathrm{vol} \%$ & $16.5 \mathrm{vol} \%$ & 28.88 & 30.07 & -4.12 \\
$10 \mathrm{vol} \%$ & $20 \mathrm{vol} \%$ & 45.83 & 45.61 & 0.48 \\
\hline
\end{tabular}

operation carried out for 30 min using BEMRF process. After finishing up to $30 \mathrm{~min}$ the scratch marks and the PLA fibers found on the surface are removed up to a larger extent. Moreover, even after $30 \mathrm{~min}$ of finishing the obtained surface is having a minute layer of polymer (as shown in Fig. 12(b)) on the surface which might be leading to some additional surface roughness as compared to the completely finished surface. Figure 12(c) represents the surface finish obtained by BEMRF process using the optimum fluid composition and finishing time of $75 \mathrm{~min}$. As seen in Fig. 12(c), all scratch marks and dullness has been removed and the surface is able to reflect more light compared to others two figures giving it a better surface finish.

\section{Conclusions}

From the above study on nanofinishing of FDM fabricated components using BEMRF process, the following conclusions can be drawn.

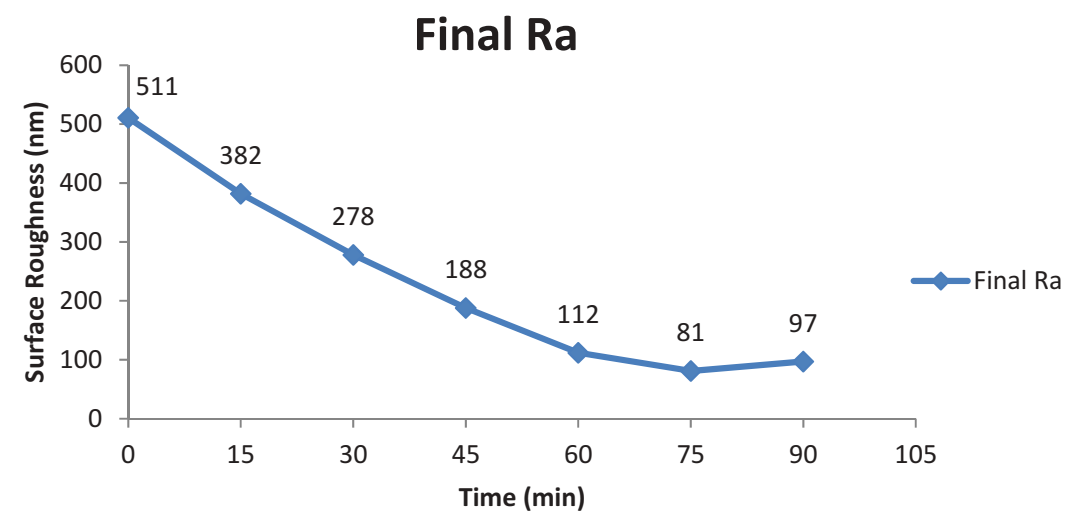

Figure 9. Finishing time vs Ra. 
(a)

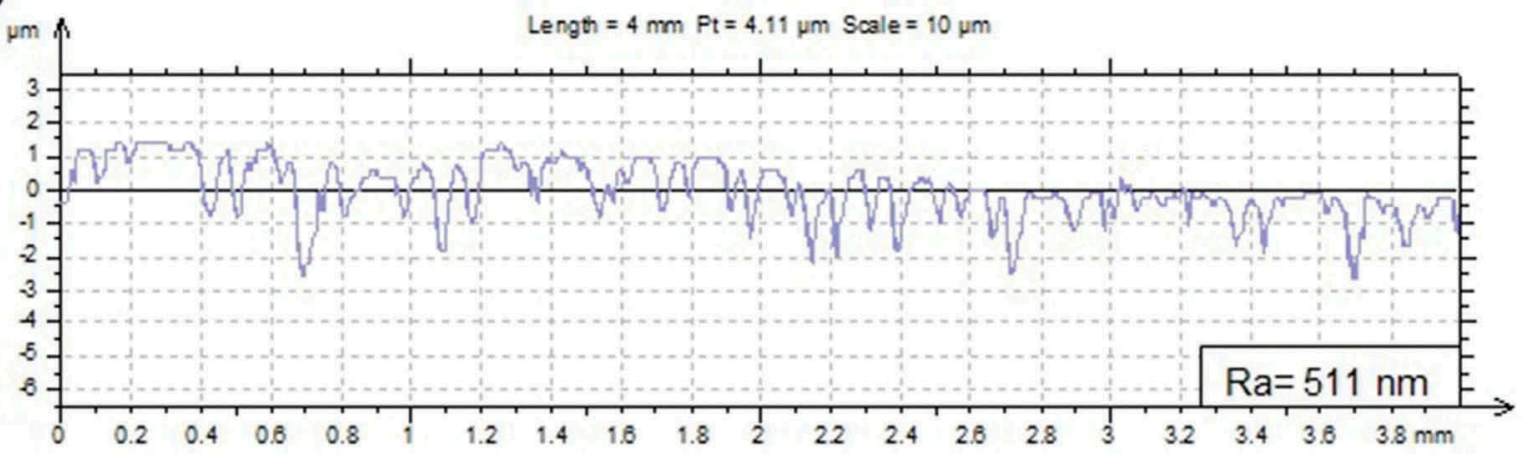

(b)

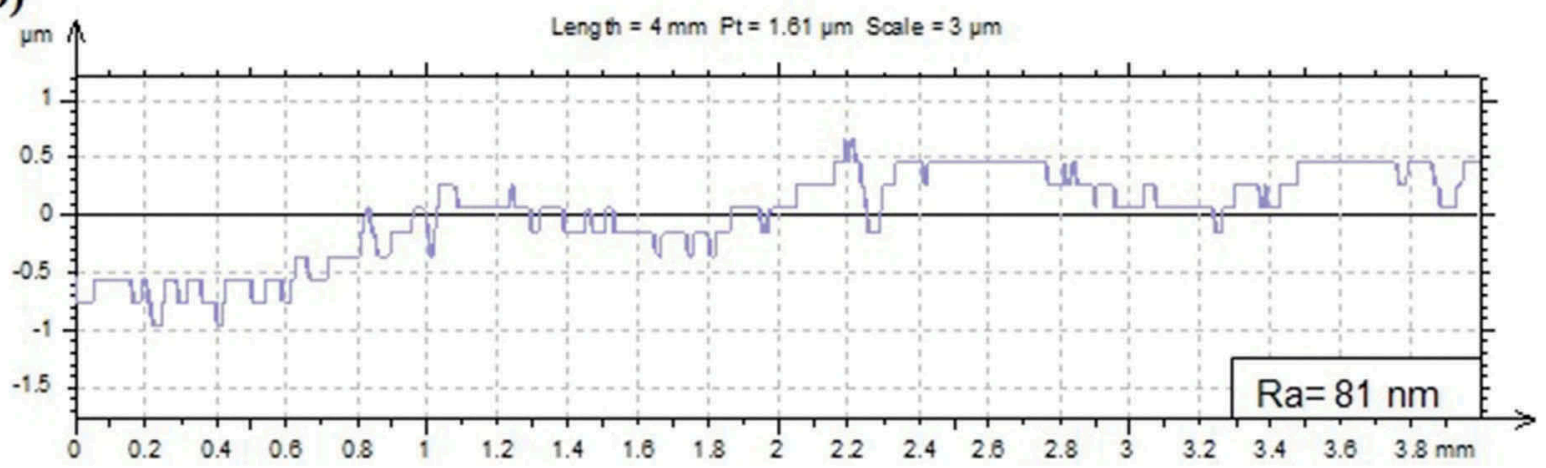

Figure 10. Roughness profile of primary finished FDM workpiece sample (a) before finishing (b) after finishing for 75 min using BEMRF process.

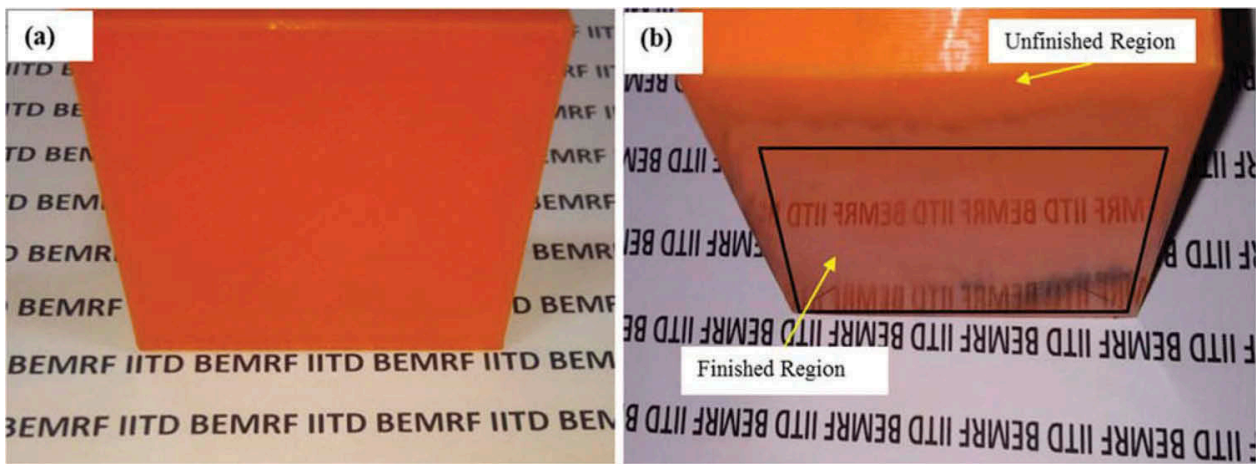

Figure 11. Actual photographs of FDM workpiece sample (a) before finishing (b) after finishing for 75 min using BEMRF process.

- For nanofinishing of FDM AM components using BEMRF machine, primary finishing operation plays a crucial role in reducing the surface roughness.

- In secondary finishing, the operation carried out for nanofinishing of FDM parts using BEMRF process both abrasive, and EIP concentration in MRP fluid contribute significantly toward the percent change in surface roughness.

- For any constant abrasive concentration, the $\% \Delta \mathrm{Ra}$ increases up to an extent and then decreases with increase in EIP concentration. Similarly, for any constant EIP concentration, increasing abrasive concentration increases the $\% \Delta \mathrm{Ra}$.

- The optimum MRP fluid composition obtained from the experimental analysis for finishing of FDM part using BEMRF process is $16.17 \mathrm{vol} \%$ of abrasives, $25 \mathrm{vol} \%$ of EIP, and $58.83 \mathrm{vol} \%$ of distilled water as the carrier fluid.

- The critical surface roughness value that can be achieved with the optimum MRP fluid composition is $\mathrm{Ra}=81 \mathrm{~nm}$. This value was achieved for $75 \mathrm{~min}$ of BEMRF. 

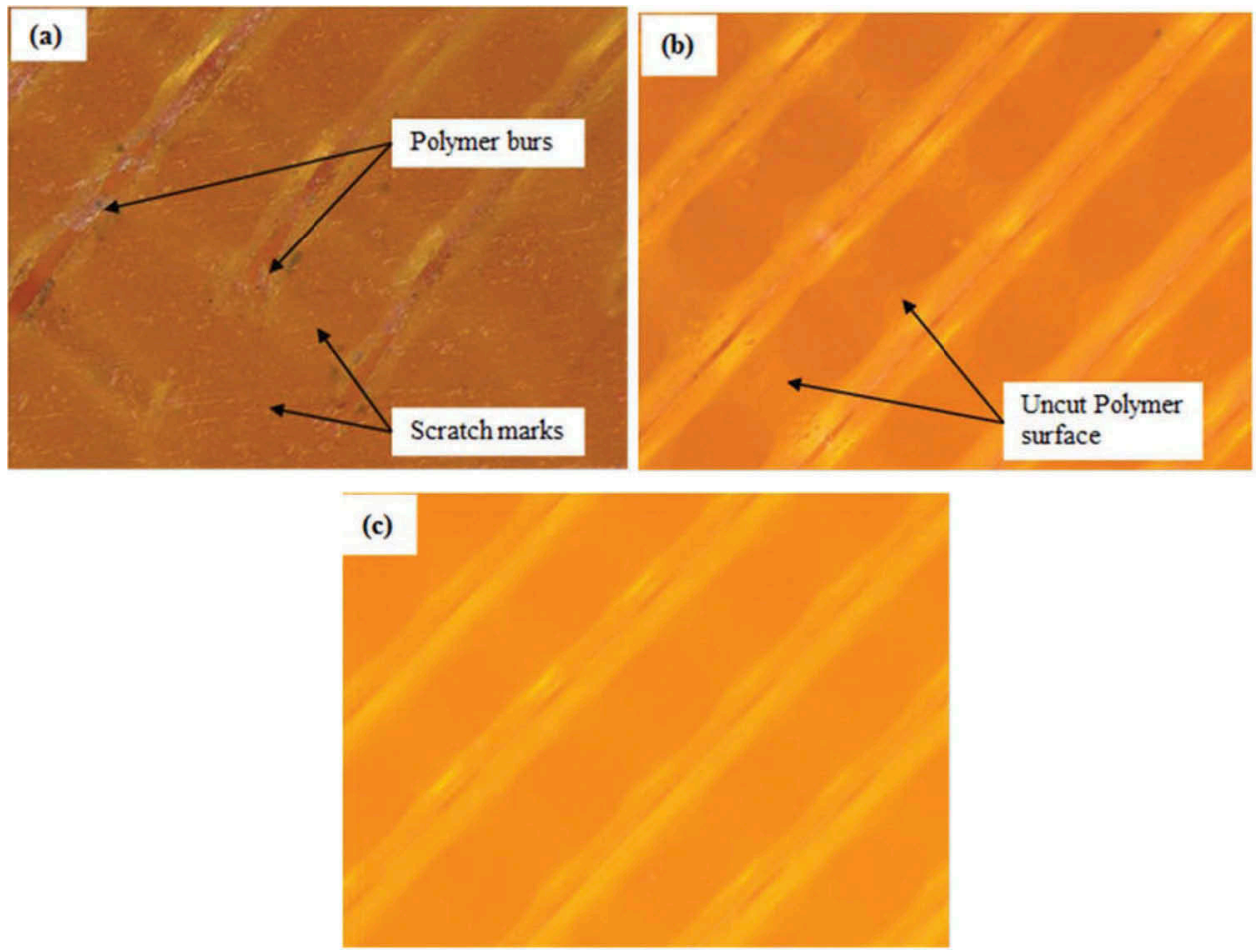

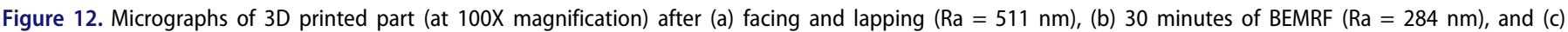
75 minutes of BEMRF $(\mathrm{Ra}=81 \mathrm{~nm})$.

- The application of low cost AM components having nanofinish requirement can be fulfilled using BEMRF process.

- The variation of spindle speed, feed, and gap between tool tip and workpiece has a substantial effect on $\% \Delta \mathrm{Ra}$ and its effect can be studied in future work.

\section{ORCID}

Aman Kumar (D) http://orcid.org/0000-0003-1991-3144

Zafar Alam (Di) http://orcid.org/0000-0002-5155-8763

Dilshad Ahmad Khan (D) http://orcid.org/0000-0002-5341-0308

Sunil Jha (D) http://orcid.org/0000-0002-4100-1320

\section{References}

[1] Horáček, M.; Charvát, O.; Pavelka, T.; Sedlák, J.; Madaj, M.; Nejedlý, J. Medical Implants by Using RP and Investment Casting Technologies. The 69th WFC 2011, 8, 107-111.

[2] Zhong, Z. W.;. Recent Advances in Polishing of Advanced Materials. Mater. Manuf. Processes 2008, 23(5), 449-456.

[3] Hopkinson, N.; Hague, R.; Dickens, P. Introduction to Rapid Manufacturing. Rapid Manuf. Ind. Revolution Digital Age 2006, $22,1-4$.

[4] Masood, S. H.; Hashmi, S., Ed. Advances in Fused Deposition Modelling, Comprehensive Materials Processing, Elsevier: Amsterdam, 2014. 69-91.

[5] Pandey, P. M.; Reddy, N. V.; Dhande, S. G. Improvement of Surface Finish by Staircase Machining in Fused Deposition Modeling. J. Mater. Process. Technol. 2003, 132(1-3), 323-331.

[6] Chohan, J. S.; Singh, R. Pre and Post Processing Techniques to Improve Surface Characteristics of FDM Parts: A State of Art
Review and Future Applications. Rapid Prototyping J. 2017, 23(3), 495-513.

[7] Sabourin, E.; Houser, S. A.; Bøhn, J. H. Adaptive Slicing Using Stepwise Uniform Refinement. Rapid Prototyping J. 1996, 2(4), 20-26.

[8] Tagore, G. R. N.; Anjikar, S. D.; Venugopal, A. Multi Objective Optimization of Build Orientation for Rapid Prototyping with Fused Deposition Modeling (FDM). In Proceedings of 17th Solid Freeform Fabrication, Austin, 6-8 August, 2007, 246-255.

[9] Kim, M. K.; Lee, I. H.; Kim, H. C. Effect of Fabrication Parameters on Surface Roughness of FDM Parts. Int. J. Precis. Eng. Manuf. 2018, 19(1), 137-142.

[10] Nancharaiah, T.; Raju, D. R.; Raju, V. R. An Experimental Investigation on Surface Quality and Dimensional Accuracy of FDM Components. Int. J. Emerging Technol. 2010, 1(2), 106-111.

[11] Galantucci, L. M.; Dassisti, M.; Lavecchia, F.; Percoco, G. Improvement of Fused Deposition Modelled Surfaces Through Milling and Physical Vapor Deposition. 1st Workshop on the State of the Art and Challenges of Research Efforts at POLIBA, 2014, 1, 87-92.

[12] Kuo, C. C.; Mao, R. C. Development of a Precision Surface Polishing System for Parts Fabricated by Fused Deposition Modeling. Mater. Manuf. Processes 2016, 31(8), 1113-1118.

[13] Garg, A.; Bhattacharya, A.; Batish, A. On Surface Finish and Dimensional Accuracy of FDM Parts after Cold Vapor Treatment. Mater. Manuf. Processes 2016, 31(4), 522-529.

[14] Singh, J.; Singh, R.; Singh, H. Investigations for Improving the Surface Finish of FDM Based ABS Replicas by Chemical Vapor Smoothing Process: A Case Study. Assembly Autom. 2017, 37(1), 13-21.

[15] Guo, J.; Bai, J.; Liu, K.; Wei, J. Surface Quality Improvement of Selective Laser Sintered Polyamide 12 by Precision Grinding and Magnetic Field-assisted Finishing. Mater. Des. 2018, 15, 138-145.

[16] Singh, A. K.; Jha, S.; Pandey, P. M. Magnetorheological Ball end Finishing Process. Mater. Manuf. Processes 2012, 27(4), 389-394.

[17] Alam, Z.; Iqbal, F.; Ganesan, S.; Jha, S. Nanofinishing of 3D Surfaces by Automated Five-axis CNC Ball End Magnetorheological Finishing Machine Using Customized Controller. Int. J. Adv. Manuf. Technol. 2018, 1-12. 
[18] Singh, A. K.; Jha, S.; Pandey, P. M. Performance Analysis of Ball End Magnetorheological Finishing Process with MR Polishing Fuid. Mater. Manuf. Processes 2015, 30, 1482-1489.

[19] Sidpara, A.; Das, M.; Jain, V. K. Rheological Characterization of Magnetorheological Finishing Fluid. Mater. Manuf. Processes 2009, 24(12), 1467-1478.

[20] Khan, D. A.; Jha, S. Synthesis of Polishing Fluid and Novel Approach for Nanofinishing of Copper Using Ball-end Magnetorheological Finishing Process. Mater. Manuf. Processes 2018, 33(11), 1150-1159.

[21] Khan, D. A.; Kumar, J.; Jha, S. Magneto-rheological Nano-finishing of Polycarbonate. Int. J. Precis. Technol. 2016, 6(2), 89-100.
[22] Singh, A. K.; Jha, S.; Pandey, P. M. Nanofinishing of Fused Silica Glass Using Ball End Magnetorheological Finishing Tool. Mater. Manuf. Processes 2012, 27(10), 1482-1489.

[23] Alam, Z.; Khan, D. A.; Jha, S. A Study on the Effect of Polishing Fluid Volume in Ball End Magnetorheological Finishing Process. Mater. Manuf. Processes 2018, 33(11), 1197-1204.

[24] Rafai, N. H.; Islam, M. N. An Investigation into Dimensional Accuracy and Surface Finish Achievable in Dry Turning. Mach. Sci. Technol. 2009, 13(4), 571-589.

[25] Boschetto, A.; Bottini, L.; Veniali, F. Finishing of Fused Deposition Modeling Parts by CNC Machining. Rob. Comput. Integr. Manuf. 2016, 1(41), 92-101. 